\title{
User Preference Survey on Staircase Rotation
}

\author{
Ping $\mathrm{An}^{1}$ and Biao Wang ${ }^{1,2}$ \\ 1. College of Architecture and Art, North China University of Technology, Beijing 100144, China \\ 2. Department of Civil Engineering, National Institute for Applied Sciences, Toulouse 31077, France
}

\begin{abstract}
Staircase is an important means of vertical transportation. Staircase design exerts a great influence on the aesthetics, transportation efficiency, user comfort and experience level. In this paper, a survey on the staircase rotation preference was conducted, based on the environment behavior studies. Different user frequencies of a pair of scissors stairs in the 2nd teaching building of North China University of Technology were analyzed. The psychological effect was evaluated and quantified, and the user preference on the two staircase rotations was then withdrawn. The survey found that the type of staircase with clockwise upstairs was much more preferred $(78 \%)$ than the other staircase rotation anti-clock upstairs. Considering different genders, the female shows a $66 \%$ higher preference inclination of this type of staircase rotation than the male. To improve the transportation efficiency of the staircase in case of fire, the result of this paper can be very constructive for the evacuation staircase rotation choice for the high-rise buildings.
\end{abstract}

Key words: Evacuation stairs, staircase rotation, user preference, environmental behavior.

\section{Introduction}

Staircase is an important part of the vertical transportation of a building. Its spatial form has a big influence on the aesthetics, transportation efficiency, user comfort and level of space experience [1, 2]. Evacuation stairs are a vital facility of the high-rise buildings and offer the very safe exit when there is a fire. The spatial layout of the stairs will directly influence the evacuation capabilities and evacuation efficiency [3, 4]. Compared with multi-layer buildings, high-rise and ultra high-rise buildings have higher evacuation requirements and are more demanding on the staircase design. The interaction between fire and human is very important in the analysis of emergency evacuation under fire condition [5]. Staircase rotation can be an important factor in transportation efficiency and user comfort. However, there is no guideline in the current building codes on the choice of staircase rotations. The impact can be important if a clear user preference exists.

Which rotation a staircase should adopt? Maybe we

Corresponding author: Biao Wang, Ph.D., lecturer, research fields: urban morphology and urban wind energy evaluation. E-mail: bwang@insa-toulouse.fr. can find some reasons to the standard running rotation in anticlockwise in the circle runway:

- Our heart is positioned on the left of our body. Therefore, the gravity centre is left-sided and the anticlockwise is preferred in order to reduce the pressure on heart. Besides, as the left leg support the body more than the right leg, it is easier to turn left than to turn right;

- Human beings are more right-handed than left-handed. Therefore, as the hand swing is advantageous to promote the running speed, the right hand is more used and the anticlockwise running rotation is more favorable;

- For us human beings, left leg is found being shorter than the right, as a result of the earth rotation and the principal habitation in the Northern Hemisphere [6].

However, these reasons cannot suggest a choice of staircase rotation because of its two directions: upstairs and downstairs. Therefore, the user preference of the staircase rotation was analyzed in this paper, based on the perspective of environmental behavior studies. Different user frequencies of a pair of scissors stairs were counted and an evaluation model was constructed, with rectification of the initial condition imbalance, 
social activity impact and psychological effects. The result would be favorable for the staircase rotation choice in high-rise buildings and the optimization of the building codes.

Since in high-rise or ultra-high-rise buildings, evacuation stairs are hardly used in practice (while the lifts are in function), the data collection of staircase usage is usually very difficult. In this case, the survey object turns to multi-storey buildings, where the staircases are frequently used and a large usage frequency can be accessible. To get the result as effective and precise as possible, the object staircases selecting for the survey and the evaluation later are of great importance.

\section{Survey and Results}

\subsection{Background}

The set of scissor-cross staircase (Figs. 1 and 2) in the 2nd TB (teaching building) of NCUT (North China University of Technology) was chosen, as the flow of students to and from there was abundant and the survey samples were rich. The staircase is actually a combination of two pairs of scissor-cross stairs, with one pair of stairs in clockwise for upstairs and the other pair in anticlockwise for upstairs. Since the two pairs of stairs share the same entrance, the research of the user preference of staircase rotation with this staircase can be very convenient and pertinent. Therefore, it was chosen for this survey.

The survey was taken from April 7-10, 2009 [7] and included five periods of time with both intensive and incompact periods, which was good for avoiding a sample bias. The main method of this survey was targeted

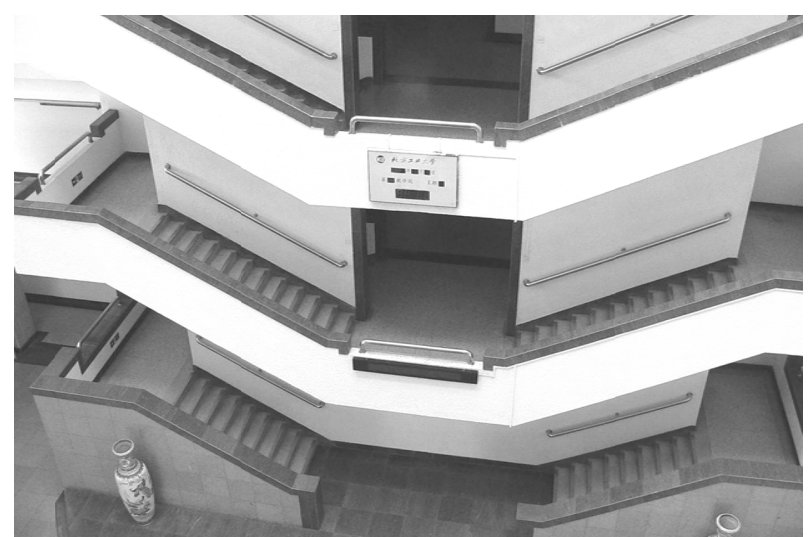

Fig. 1 Perspective of the scissor-cross staircase, 2nd TB, NCUT.

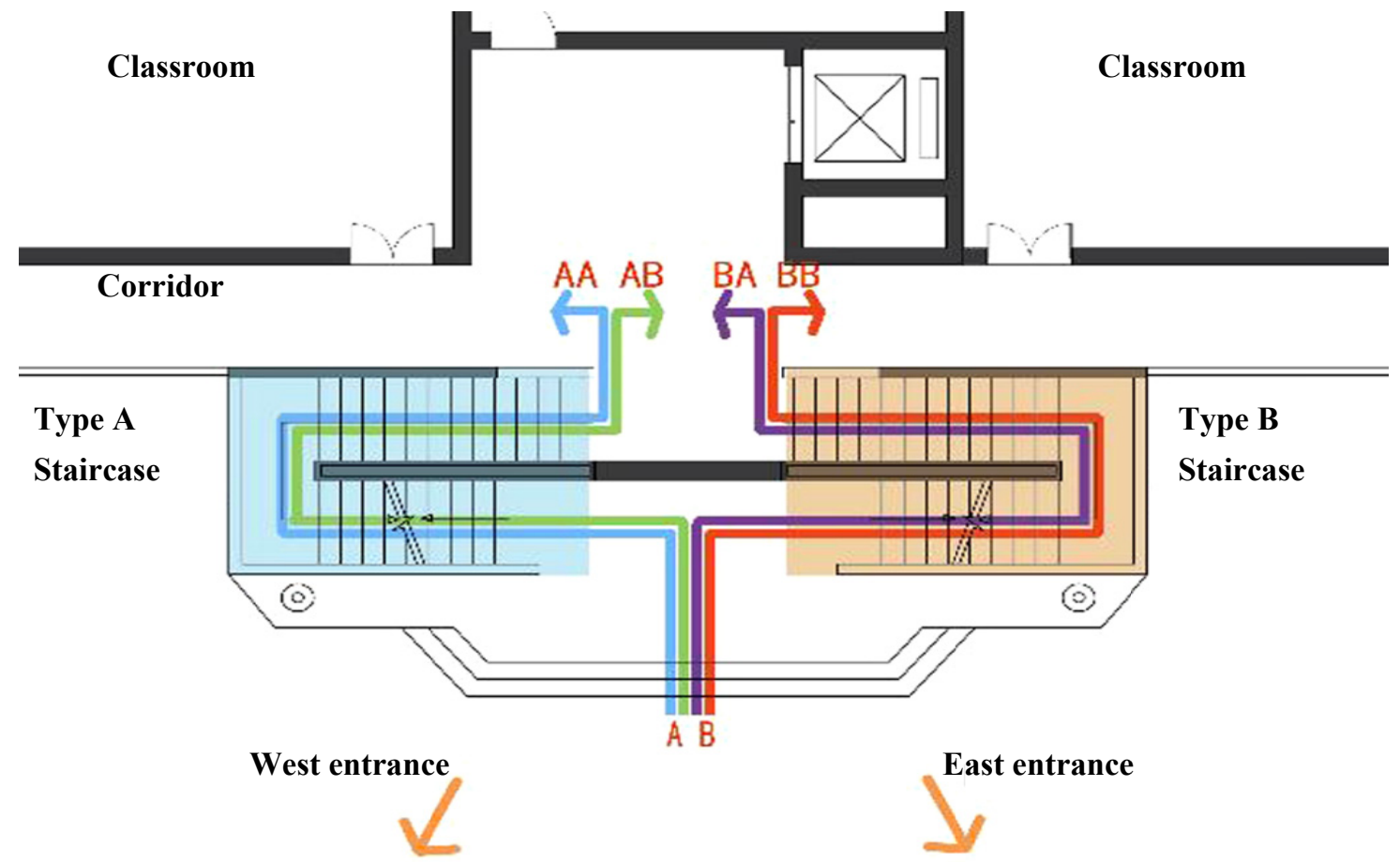

Fig. 2 Plan (ground floor) of the scissor-cross staircase, 2nd TB, NCUT. 
Table 1 Time and main feature of different periods of survey.

\begin{tabular}{|c|c|c|c|c|c|c|}
\hline \multirow[b]{2}{*}{$\begin{array}{l}\text { No. of } \\
\text { survey }\end{array}$} & \multirow[b]{2}{*}{ Time } & \multirow[b]{2}{*}{ Flow feature } & \multicolumn{3}{|c|}{ Evaluation impact } & \multirow[b]{2}{*}{$\begin{array}{l}\text { - Reference } \\
\text { model }\end{array}$} \\
\hline & & & $\begin{array}{l}\text { Unbalanced usage of } \\
\text { the building }\end{array}$ & Shortcut effect & $\begin{array}{l}\text { Unbalanced flow of } \\
\text { the hall entrance }\end{array}$ & \\
\hline 1 & $\begin{array}{l}\text { April 7, } \\
\text { 15:40-16:40 }\end{array}$ & $\begin{array}{l}\text { In class in the afternoon, not } \\
\text { crowded }\end{array}$ & Upstairs & $\begin{array}{l}\text { Upstairs, } \\
\text { downstairs }\end{array}$ & 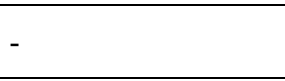 & - \\
\hline 2 & $\begin{array}{l}\text { April 7, } \\
\text { 18:30-19:30 }\end{array}$ & $\begin{array}{l}\text { Evening self-study period } \\
\text { not crowded }\end{array}$ & Upstairs & $\begin{array}{l}\text { Upstairs, } \\
\text { downstairs }\end{array}$ & - & - \\
\hline 3 & $\begin{array}{l}\text { April 8, } \\
\text { 18:03-19:43 }\end{array}$ & $\begin{array}{l}\text { Evening self-study period, } \\
\text { not crowded }\end{array}$ & Upstairs & $\begin{array}{l}\text { Upstairs, } \\
\text { downstairs }\end{array}$ & - & - \\
\hline 4 & $\begin{array}{l}\text { April 10, } \\
7: 15-8: 15\end{array}$ & $\begin{array}{l}\text { Morning reading, attending } \\
\text { the first class, crowded }\end{array}$ & Upstairs & 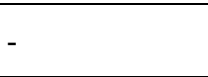 & - & $\begin{array}{l}\text { Upstairs, } \\
\text { downstairs }\end{array}$ \\
\hline 5 & $\begin{array}{l}\text { April 9, } \\
7: 24-8: 04\end{array}$ & $\begin{array}{l}\text { Morning reading, attending } \\
\text { the first class, crowded }\end{array}$ & - & - & All the data together & 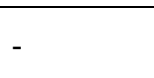 \\
\hline
\end{tabular}

observation and visual counting, assisted with video record when the flow was heavy and the immediate counting was difficult. The time periods and the corresponding features of the flow are given in Table 1. The application situation of the data in different surveys are also presented.

\subsection{Results of the Survey}

According to the different stairs choices (of rotation), different outlet direction and difference in upstairs and downstairs, the records of this survey were sorted in eight classes: $\mathrm{AA}, \mathrm{AB}, \mathrm{BB}$ and $\mathrm{BA}$, for both the routes upstairs and downstairs (Fig. 2). The results of five surveys were given in the Figs. 3a-3e.

The group of people, rather than the individual, was chosen as the counting unit for the general preference, as the behavior of individual is easily affected by the group which he/she is in, and generally, the same behavior of all the members of the group (choosing the same route) is decided by the leader, or called the first decision maker. In this sense, to avoid the error from the distorted will of individuals, this survey considered the group unit with the same route and evident spatial gathering among the members in the group. One individual was considered as one group.

As to analyze the results of different genders, not liking the evaluation of the general preference, we chose individual as counting unit. Considering the general balance of gender for the students in NCUT (in 2014 , the gender proportion of male to female is $1: 1.02$ ) [8], and the public courses mission of the 2 nd teaching building, the gathering in group has little influence in the gender difference analysis in an overall way.

\section{Ideal Modeling and Rectification}

To evaluate the user preference of staircase rotation in an objective and accurate way, an ideal model should be set up. Three main conditions are to be respected for the ideal model:

(1) Ensure the same inlet condition, which means the users have the same selective advantage over the two pairs of stairs: equal distances reaching the two entrances of the two pairs of stairs;

(2) Ensure the same motivation, which means the users have equal needs and consciousness when they plan to take the stairs. For example, the distribution of the places where they want to go should be even at the two sides of staircase exit;

(3) Ensure the same outlet condition, which means the users have equal distances between the exits of the two pairs of stairs and the places where they want to go.

The first condition may be influenced by the inequality of the two entrances of flow: west entrance and east entrance. Besides, as shown in Fig. 4, the straight line distances between the two hall entrances and the two pairs of stairs are not equal, e.g., between the lines A'A and A'B. While the difference between the lines A'A and A'B, and the difference between the lines $\mathrm{AA}$ and $\mathrm{AB}$ are not equal, the level of shortcut effect should be different. Therefore, the influence of shortcut effect should be evaluated, with the precision of the direction, upstairs or downstairs. The third condition 


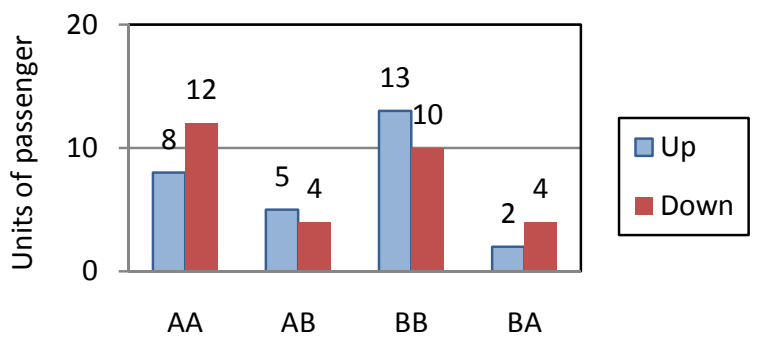

(a)

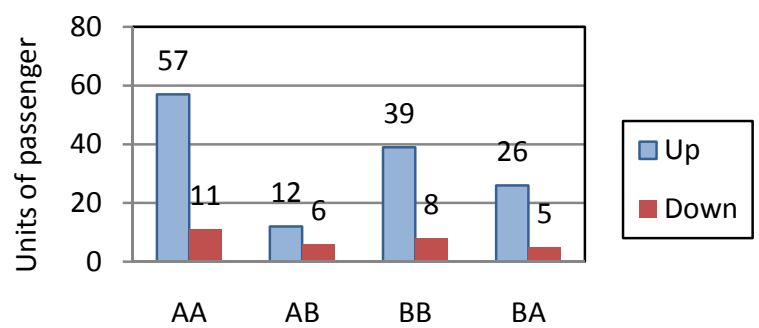

(b)

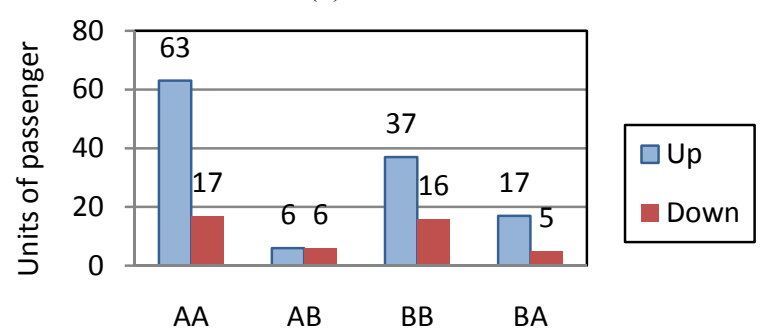

(c)

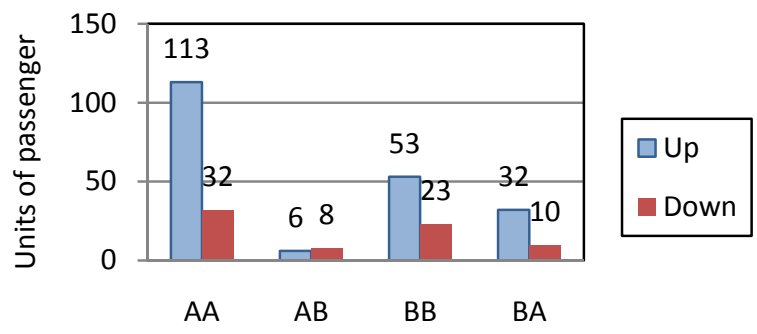

(d)

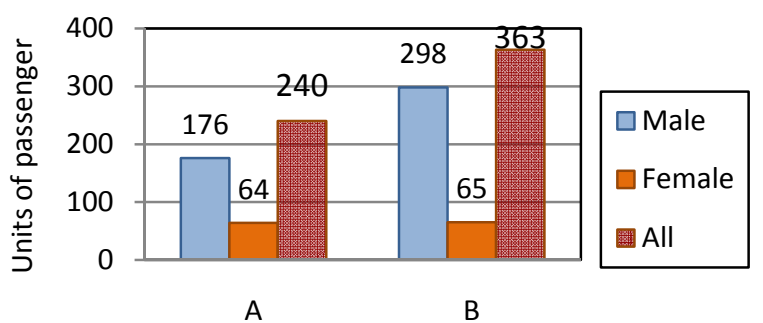

(e)

Fig. 3 Number of units in different routes: (a) 1st survey; (b) 2nd survey; (c) 3rd survey; (d) 4th survey; (e) 5th survey.

may be influenced by the inequality of usage between the classrooms or offices in two sides of the building.
While the inequality of usage of the two sides of the building exists, the future consciousness may influence the second condition. In the following, we are going to evaluate these impact factors for the ideal model.

In the following, we will present different impacts that influence the results of surveys. The fourth survey will be set as the reference model. Starting from the total quantity of the reference model, the ideal model was adjusted with consideration of the different impact factors. As comparing between the two models, the questioned preference of staircase rotation would be analyzed (Fig. 5).

\subsection{Impact of Unbalanced Usage of the Building}

As being observed, the function of the west side and east side of the rooms in the 2 nd teaching building was not equally distributed, which leads to the inequality of usage. To find out the inequality, we evaluate the ratio of the total number of west outlet flow to that of east outlet flow in the case, which can be marked as:

$$
F=\frac{\sum_{i} F_{\text {west }}}{\sum_{i} F_{\text {east }}}=\frac{\sum_{i}(A A+B B)}{\sum_{i}(B B+A B)}
$$

where, $i$ represents the sequence number of the survey that is taken in calculation, $F_{\text {west }}$ and $F_{\text {east }}$ represent respectively the flow of the west and the flow of the east, $A A, A B, B B$ and $B A$ represent respectively the flow of each route as marked in Fig. 2.

Using the first four surveys, we got an integrated ratio of the usage inequality when going upstairs:

$$
F_{u p}=\frac{\sum_{4} F_{\text {west }}}{\sum_{4} F_{\text {east }}}=1.86
$$

$F=(8+2+57+26+63+17+113+32) /(5+13+$ $12+39+6+37+6+53)=1.86$. It shows that the usage of the west side rooms is $86 \%$ higher than that of the east.

A reference can be given while we consider the data of downstairs:

$$
F_{\text {down }}=\frac{\sum_{4} F_{\text {west }}}{\sum_{4} F_{\text {east }}}=1.19
$$

However, as the surveys were all undertaken in the period of class or attending for class, the crowd downstairs 


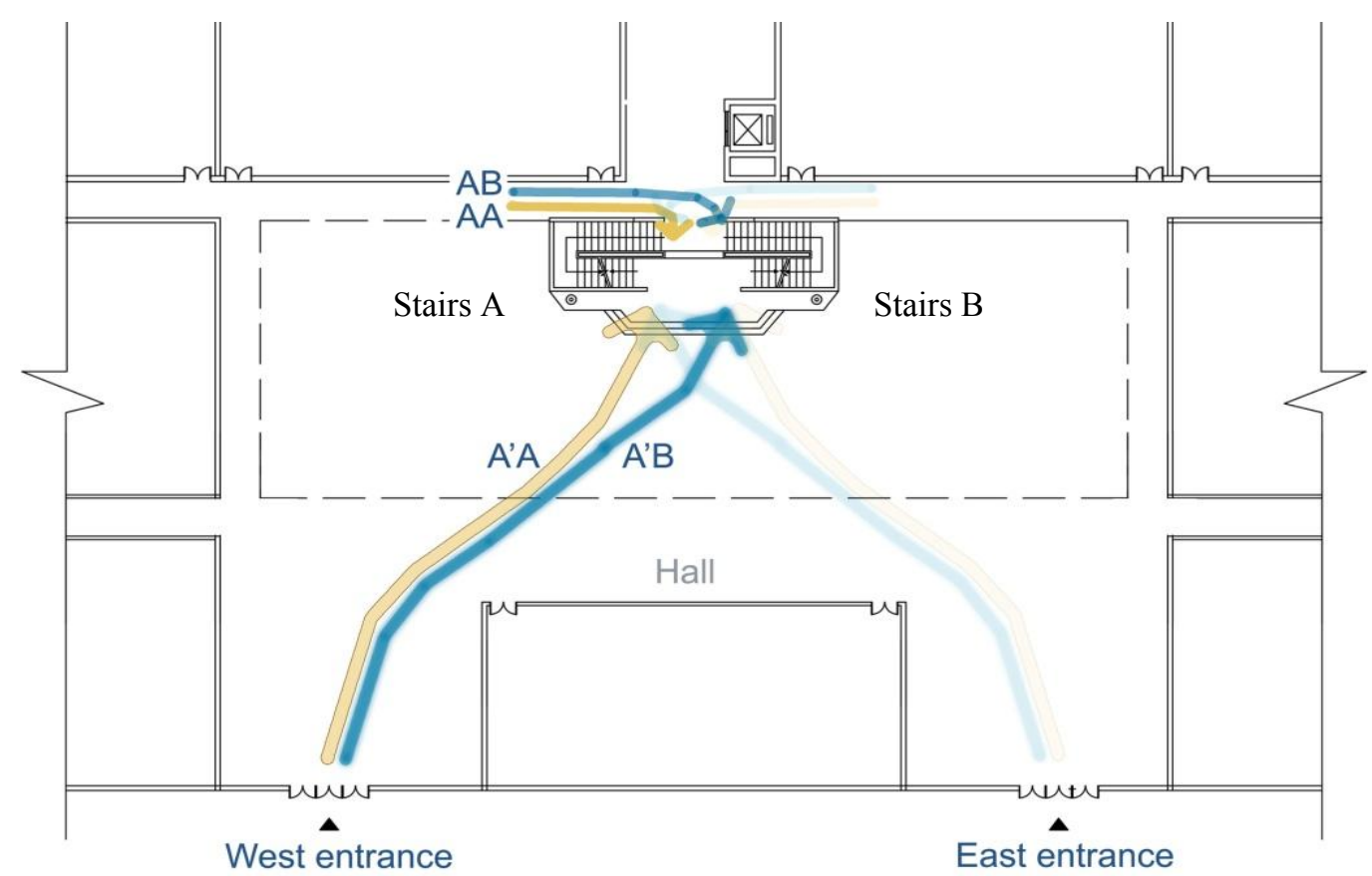

Fig. 4 Different routes on plan under the influence of the shortcut effect.

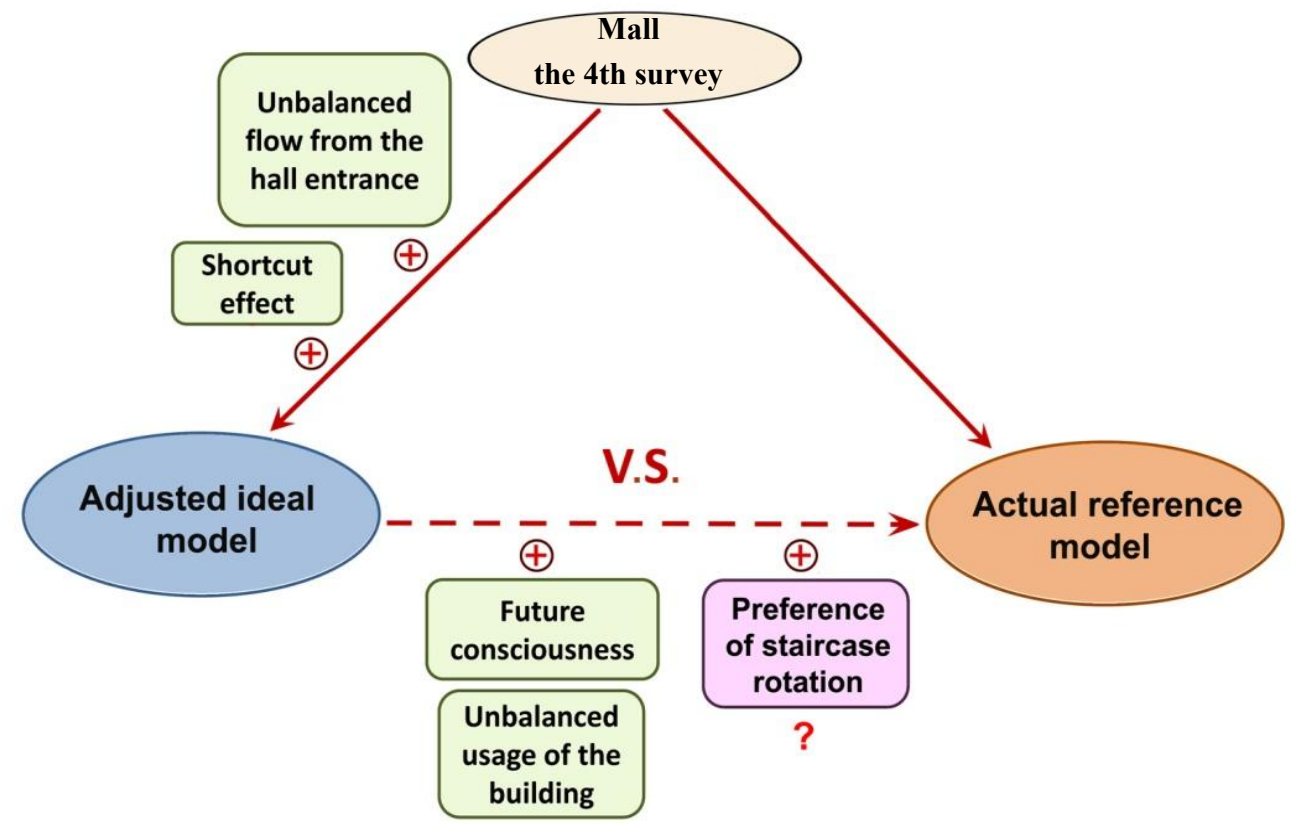

Fig. 5 Process of adjustment of the ideal model with different impacts.

was very small. In addition, we did not choose the period of dismiss because, at that time, it was very crowded and people had little space for their free choice, the preference of the stairs was then hardly expressed. Therefore, we take the upstairs data as the calculation of the impact of unbalanced usage of the building.

\subsection{Impact of Shortcut Effect}

According to the effectiveness optimization principle [9], we have the instinct of the shortcut intention, though sometimes it may not be fully expressed in some occasions. In this case, we use the data of downstairs to evaluate the expression of human 
instinct of shortcut. The shortcut effect can be evaluated by the difference between the totality of flow downstairs selecting the stairs at the same side, and the totality of flow downstairs selecting the stairs at the opposite side. The proportion of population with shortcut effect $\left(R_{\text {cut }}\right)$ in the overall survey group is:

$$
R_{\text {cut }}=\frac{M_{\text {cut }}}{M_{\text {all }}}=\frac{M_{\text {same }}-M_{\text {opp }}}{M_{\text {all }}}=\frac{(A A+B B)-(B A+A B)}{A A+A B+B B+B A}
$$

where, $M_{\text {cut }}$ represents the total population who took shortcut, $M_{\text {same }}$ represents the population who took the staircase the same side as from which he/she entered in, while the and $M_{\text {opp }}$ represents the population who took the staircase of the opposite side from where he/she entered in, $M_{\text {all }}$ represents the total sample of the survey.

We took the data of the first three surveys as the data source here, where the crowd was sparse and had big freedom for choice. In the fourth survey, the flow was very crowded and intermixed with both flow upstairs and flow downstairs, and people's behavior was easily misled or interfered by others, in the limited evacuation space. Therefore, the fourth survey was not considered for the evaluation of shortcut effect.

Then the percentage of population who expressed in their behavior the shortcut mind in the first three surveys for the routes upstairs $\left(R_{\text {cut-up }}\right)$ is:

$$
R_{\text {cut }-u p}=\frac{1}{3} \sum_{3} R_{c u t-u p}=\frac{1}{3}(50 \%+43 \%+68 \%)=54 \%
$$

If we consider the situation of downstairs, the percentage of shortcut $\left(R_{\text {cut-down }}\right)$ is:

$$
R_{\text {cut-down }}=\frac{1}{3} \sum_{3} R_{\text {cut-down }}=\frac{1}{3}(47 \%+31 \%+50 \%)=43 \%
$$

As the percentages of shortcut effect in the six cases vary in a rational value, the results are considered valid.

\subsection{Impact of Unbalanced Flow from the Hall Entrance}

As being observed, the frequency of usage of the east entrance of the hall was obviously higher than that of the west. The main reason was found that all the dormitories and cafeterias locate at the east side of the campus, where the density of population is much higher than in the laboratories and teaching buildings that locate in the west part. Because of the factor of shortcut effect, this unbalanced layout gives a big difference of the entrance flow and therefore a big influence to the will of the stairs choice. We used the result of the fifth survey, which counted the unit by individuals and was therefore more appropriate to reveal the unbalanced population distribution. In the period of the survey, the ratio of west entrance total flow to that of east entrance was: $R_{w-e}=37 / 566=1 / 15.3$. That is to say, at the chosen period, the east flow population is 15.3 times that of the west flow.

\subsection{Impact of the Future Consciousness}

How many people do they foresee clearly what they are going to do before going upstairs? Because of the hint of stairs' position and the mind of shortcut, people are used to select the flight of stairs with the same direction of their expected destination. That is to say, when the destination is at the right side of the stairs, he/she inclines to choose the right flight of stairs, even though this does not cut the distance actually. Actually, the mind of shortcut belongs to the instinctive level and concerns mainly the near interests, while the future consciousness belongs to the cognitive level and concerns the relative long-term interests [10].

To facilitate the building of the ideal model, we defined the level of the future consciousness expression as $R_{c o n}$. It is closely connected with the unbalanced usage of the 2 nd teaching building $F$ and the unbalanced flow of the hall entrance $R_{w-e}$. However, it is difficult to evaluate it directly from the data of the surveys as the evaluation of the shortcut effect.

\subsection{Adjusting the Ideal Model}

Because the entrance flow distribution varied with different periods, so we chose the statistics of the fourth survey, which were taken in almost the same period as the fifth survey, to be our reference model. Only the total number of units in the fourth survey is taken for 
the initial condition of the ideal model. We would adjust the ideal model with different impacts mentioned above and compare it with the actual reference model. For ideal model with routes upstairs, $M_{\text {all-up }}=204$, while for the model with routes downstairs, $M_{\text {all-down }}=73$. With the ratio of inequality of entrance flow that is found in the fifth survey, we can calculate the original inlet population of both sides of entrance for the model upstairs:

$$
\begin{aligned}
& M_{\text {west }}=M_{\text {all }} \frac{R_{w-e}}{1+R_{w-e}}=204 \times \frac{1}{16.3}=12.5 \\
& M_{\text {east }}=M_{\text {all }} \frac{1}{1+R_{w-e}}=204 \times \frac{15.3}{16.3}=191.5
\end{aligned}
$$

Therefore, after the consideration of the shortcut effect, the number of units in the four routes of the ideal model are respectively as follows:

$$
\begin{array}{r}
(A A)^{\prime}=R_{\text {cut }-u p} M_{\text {west }}+\frac{1}{4}\left(1-R_{\text {cut }-u p}\right) M_{\text {all }}=30.1 \\
(A B)^{\prime}=(B A)^{\prime}=\frac{1}{4}\left(1-R_{\text {cut -up }}\right) M_{\text {all }}=23.5 \\
(B B)^{\prime}=R_{\text {cut -up }} M_{\text {east }}+\frac{1}{4}\left(1-R_{\text {cut -up }}\right) M_{\text {all }}=126.9
\end{array}
$$

The ratio of total number of units who took the Staircase A and the number of units who took the Staircase B is then found:

$$
R_{\text {idea }(a-b)}=\frac{M_{a}}{M_{b}}=\frac{(A A)^{\prime}+(A B)^{\prime}}{(B B)^{\prime}+(B A)^{\prime}}=\frac{53.6}{150.4}=\frac{1}{2.81}
$$

However, in the actual case of the fifth survey, the corresponding ratio is:

$$
R_{\text {idea }(a-b)}=\frac{M_{a}}{M_{b}}=\frac{119}{85}=\frac{1}{0.71}
$$

If we define the ratio of preference of the Type A Staircase to that of the Type B Staircase as $R_{a-b}$, and take consideration of the level of the future consciousness $R_{c o n}$ and the unbalanced usage of the building $F$, then the function between the adjusted ideal model and the actual reference model can be expressed as follows:

$$
\frac{R_{\text {ide } a(a-b)}}{R_{a-b}\left(\frac{F}{R_{\text {con }}}\right)}=R_{\text {ref }(a-b)}
$$

then,

$$
R_{a-b}=\frac{R_{r e f(a-b)} F}{R_{\text {idea }(a-b)} R_{c o n}}
$$

As $0<R_{\text {con }}<100 \%$, we found $R_{a-b}>2.13$.

That means the preference of the Type A Staircase for the route upstairs is 2.13 times of that of the Type B Staircase.

In the same way, we can adjust the ideal model with routes downstairs and compare it with the corresponding actual reference model. We found out the ratio of preference of the Type A Staircase for the ideal model with routes downstairs:

$$
R_{a-b}^{\prime}>1.43
$$

That means the preference of the Type A Staircase for the route downstairs is 1.43 times of the preference of the Type B Staircase. Therefore, for both upstairs and downstairs, Type A Staircase is preferred than Type B. The average amount of preference of Type A over Type B was found bigger than $78 \%$.

\subsection{Different Preferences in Gender}

Based on the fifth survey, the ratios of preference of the Type A Staircase to that of the Type B Staircase for the two genders are:

$$
\begin{aligned}
& R_{\text {male } a-b}=\frac{176}{298}=\frac{1}{1.69} \\
& R_{\text {female } a-b}=\frac{64}{65}=\frac{1}{1.02}
\end{aligned}
$$

then we found $R_{\text {female } a-b}>R_{\text {male } a-b}$, and then the level of preference of the Type A over the Type B for females was found $66 \%$ bigger than for males. Considering the various impacts mentioned above, the absolute values of $R_{\text {male } a-b}$ and $R_{\text {female } a-b}$ here have no importance.

According to the survey and analysis above, we conclude that people prefer to choose the Type A Staircase (clockwise upstairs and anticlockwise downstairs) much more (78\%) than the Type B Staircase (clockwise downstairs and anticlockwise upstairs). The females choose the Type A much often $(67 \%)$ than the males. Thus, if the results conducted are credible, in order to match with the public behavior and 
Table 2 A survey of the staircase rotation on the campus of NCUT.

\begin{tabular}{llll}
\hline Building & \multicolumn{3}{l}{ Number of Type Number of Type Number } \\
& A Staircase & B Staircase & of floors \\
\hline $\begin{array}{l}\text { No.1 Teaching } \\
\text { Building }\end{array}$ & 2 & 2 & 3 \\
$\begin{array}{l}\text { No.2 Teaching } \\
\text { Building }\end{array}$ & 2 & 3 & 5 \\
$\begin{array}{l}\text { No.3 Teaching } \\
\text { Building }\end{array}$ & 3 & 1 & 5 \\
No.4 Teaching & 1 & 4 & $5 / 15$ \\
Building & 1 & & \\
No.5 Teaching & 2 & 2 & 15 \\
Building & 2 & & 4 \\
Internship & 0 & 2 & 5 \\
Building & & & \\
Electrical & 2 & 0 & 6 \\
Laboratory & & 3 & 6 \\
No.7 Apartment & 0 & 0 & 13 \\
No.8 Apartment 3 & 1 & \\
No.9 Apartment & 1 & &
\end{tabular}

improve the evacuation efficiency of the stairs, the evacuation stairs of the high-rise buildings would better be the Type A stairs, and for those places or architectural spaces where females are dominant, the stairs with rotation as the Type A Staircase seems more attractive.

\section{Discussions}

What is the situation in reality, concerning the rotation of staircases? A survey of the staircases in different buildings in this campus was carried out as shown in Table 2. From the table, we can see there are two tendencies in the layout of the stairs:

(1) The feature of symmetry, as shown in the No.1,2 and 5 Teaching Buildings and the No. 9 Apartment. While the building plan is symmetrical, architects have the habit of using the tool "mirror" in AutoCAD;

(2) The feature of identity, as shown in the internship buildings, electrical laboratory and the No. 7 and 8 Apartments. While the building plan is asymmetric, architects are used to applying the tool "copy" in AutoCAD.

Anyhow, none of them have paid attention to the different rotation of Types A and B Staircases. In fact, nowadays, when an architect design a pair of staircase, the points that he/she considers are the building space, height of each floor, staircase form and evacuation demand. Hardly he/she cares about the rotation of the staircase on the problem of evacuation efficiency and usage comfort, unless it is related to the usage of space on plan. The current building codes have no proposition neither demand on that.

\section{Conclusions}

In this paper, a case of scissor-cross staircase in a multi-storied building was chosen for the survey on the problem of staircase rotation choice. Several periods of time were taken for the surveys in order to get a reasonable result. Based on the methods of environment-behavior studies, the ideal model was discussed and different impact factors were taken into consideration for adjustment. With comparison of the adjusted ideal model and the actual reference model, the questioned preference of staircase rotation was analyzed. The results show that the Type A Staircase with clockwise upstairs is much more preferred by people than the Type B Staircase with clockwise downstairs. In addition, the females choose the Type A much often than the males do. The result would be interesting for promoting evacuation efficiency of the staircase in high-rise buildings.

Though this article analyzed carefully the different impacts for the ideal model, it still has its limits:

- compatibility between the data of the fourth and of the fifth surveys, even though the feature of the period is mostly the same;

- limit of time for sample collection, which might lead to the inaccuracy of the model.

Nevertheless, concerning with environmental behavior and architectural detail design, this paper had a careful diagnosis on the potential problems of staircase rotation in the real world architectural practice, which is a positive journey and exploration in itself.

\section{References}

[1] Zhuang, W. 2000. Introduction to Architecture Programming. Beijing: China Water Power Press. (in 
Chinese)

[2] Yang, G. 2002. Communication and Space. Translated by He, R. Beijing: China Construction Industry Press. (in Chinese)

[3] Ding, Y., Yang, L., Weng, F., Fu, Z., and Rao, P. 2015. "Investigation of Combined Stairs Elevators Evacuation Strategies for High Rise Buildings Based on Simulation." Simulation Modelling Practice and Theory 53 (4): 60-73.

[4] Cłapa, I., Cisek, M., Tofilo, P., and Dziubiński, M. 2015. "Firefighters Ascending and Evacuation Speeds during Counter Flow on Staircase." Safety Science 78 (10): 35-40.

[5] Yang, P., Li, C., and Chen, D. 2013. "Fire Emergency Evacuation Simulation Based on Integrated Fire-Evacuation Model with Discrete Design Method." Advances in Engineering Software 65 (11): 101-11.

[6] Lin, Y. F. 2011. "Why All the Tracks Are in the
Counterclockwise Direction.” Baidu, Inc. Accessed May 10, 2015. http://zhidao.baidu.com.

[7] Wang, B., and Zhang, B. 2010. "An Survey on Use-Preference of Staircases with Different Rotations." In International Symposium for Environment-Behavior Studies, 532-6.

[8] Website of the College Entrance Examination of Guangxi. 2014. "The Ranking of Proportions of Female Students in Beijing Universities." Website of the College Entrance Examination of Guangxi. Accessed May 10, 2015. http://www.gxeduw.com/gaokao/2014/107602.html.

[9] Chang, H., trans. 1990. Architecture Environmental Psychology. Beijing: China Construction Industry Press. (in Chinese)

[10] Xu, F. 2007. Space Configuration Research of Campus Square in Perspective of Human Behavior. Chongqing: Chongqing University Press. (in Chinese) 